\title{
IRIDOIDS WITH ANTIMICROBIAL ACTIVITY FROM PLUMERIA ALBA L.
}

Mohammad S. Afifi, Osama M. Salama, Ahmad A. Gohar, and Amani M. Marzouk

Department of Pharmacognosy, Faculty of Pharmacy, Mansoura University, Mansoura 35516, Egypt

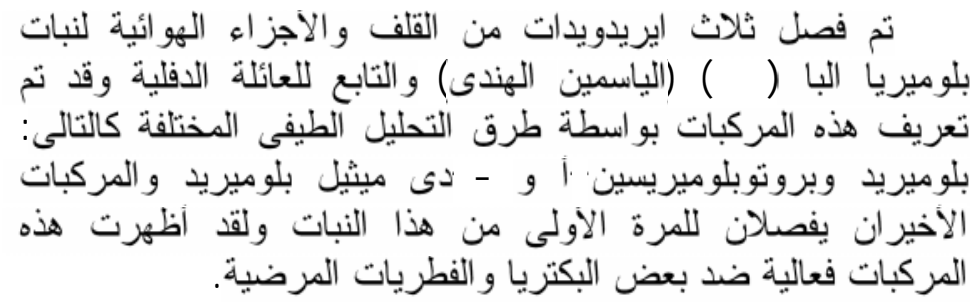

Three major iridoids; viz. plumieride, protoplumericin A and plumieride acid were isolated from the bark and leaves of Plumeria alba L. Protoplumericin A and plumieride acid are reported for the first time from the titled plant. These compounds were identified through different chemical and spectroscopic methods. They displayed distinct activity against some pathogenic bacteria and fungi.

\section{INTRODUCTION}

Plumeria is a small tree native to West Indies and Central America. The extracts of different parts of the plants have been used as purgative, abortificient, emmenagogue, and febrifuge and as antiphlogestic. ${ }^{1}$ The genus Plumeria L., Apocynaceae, is reported for its iridoid content. Some of the plumeria-type iridoids were found to be antifungal, algaecidal and plant growth inhibitors. ${ }^{2 \& 3}$ Other constituents reported from Plumeria include alkaloids; ${ }^{4}$ flavonoids ${ }^{5}$ and lignans. ${ }^{6}$ The plant is cultivated in Egypt as an ornamental, for the strongly scented flowers. Reviewing the literature, little could be traced concerning the constituents of Plumeria species growing in Egypt, ${ }^{7}$ so Plumeria alba L. was chosen for phytochemical and biological investigation. 


\section{EXPERIMENTAL}

\section{General}

Mps are uncorr. UV, $\lambda_{\max }$ in $\mathrm{MeOH}, \quad \mathrm{IR}, \quad v-\mathrm{cm}^{-1}$, spectra were recorded in $\mathrm{KBr}$ discs, ${ }^{1} \mathrm{H}$ and ${ }^{13} \mathrm{C}$ NMR spectra were recorded at 270 and 67.5 MHz, respectively (Jeol FX270, Japan). FAB MS spectra were measured using a UIC 002002 instrument, USA.

\section{Plant material}

Stem bark and leaves of $P$. alba $\mathrm{L}$. were collected from trees cultivated in the campus of Mansoura University and identified by Prof. I. Mashaly (Plant Biology, Dept., Faculty of Science, Mansoura University). A voucher specimen was deposited in the Herbarium of the Department of Pharmacognosy, Faculty of Pharmacy, Mansoura University.

\section{Isolation of the iridoid fraction}

Fresh homogenised stem bark (2.2 $\mathrm{Kg})$ and dried powdered leaves $(890$ g) of Plumeria alba L. were extracted separately with boiling ethanol (10 and $51 \times 3$ respectively). The combined extracts were concentrated separately under reduced pressure at $40^{\circ}$. Each extract diluted with water, defatted with petrol (b.r 60-80 $)$ and then partitioned with chloroform and ethyl acetate. The mother liquor of the leaves extracts was further partitioned with n-butanol. Chromatographic separation of the ethyl acetate extract of the stem bark $(6.0 \mathrm{~g})$ was performed on silica gel, $140 \mathrm{~g}$, using ethyl acetate and a mixture of methanol-water in the ratio of 16.5:13.5. The proportions of the methanol-water mixture were increased from $5-30 \%$ in the EtOAc and $50 \mathrm{ml}$ fractions were collected. The fractionation led to the isolation of one major compound (1) from fractions 6-20. Chromatographic separation of the n-butanol extract of the leaves on silica gel CC using the same eluent and collecting fractions of $50 \mathrm{ml}$, led to the isolation of three compounds, 1 (from fractions 11-14, B), 2 (from fractions 27-29, D) and $\mathbf{3}$ (from fractions 42-54, E). The obtained fractions were monitored by TLC using ethyl acetate-methanolwater (100:16.5:13.5) as solvent system and visualized by spraying with $1 \%$ vanillin-sulphuric acid reagent. Similar fractions were bulked together and compounds further purified as follows:

Compound 1: Crude material was obtained in fractions 6-20 of the ethyl acetate extract of the bark $(4.0 \mathrm{~g})$ (10\% methanol-water mixture in ethyl acetate) was re-chromatographed (1.0 g) on silica gel column $(40 \mathrm{~g})$ and eluted with mixtures of chloroformmethanol-water to afford pure compound in successive fractions eluted with chloroform-methanolwater $(80: 20: 2)$ as micro-needle crystals $(600 \mathrm{mg})$. Another crop of $\mathbf{1}$ $(110 \mathrm{mg})$ was isolated from fraction B of the n-butanol extract of the leaves.

\section{Acetylation}

$100 \mathrm{mg}$ of 1 were acetylated with $5 \mathrm{ml}$ of a mixture of acetic anhydride 
and pyridine (1:1). The mixture was stirred for three hours and then kept in the dark overnight at room temperature. The acetylation product was purified by CC (silica gel, toluene-ethyl acetate mixtures). Pure 1 acetate was crystallized from methanol as colourless needles $(80 \mathrm{mg})$.

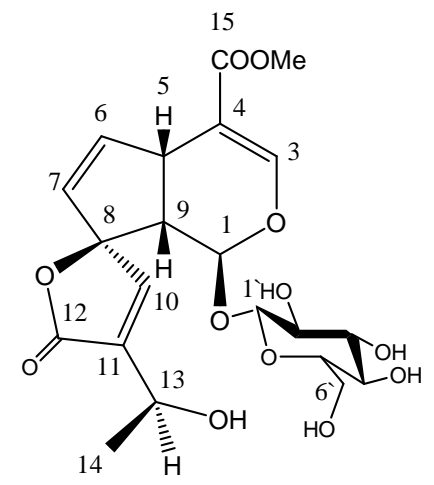

1

Compound 2 was obtained in fraction $\mathrm{D}$ of the n-butanol extract of the leaves $(250 \mathrm{mg})$ eluted with ethyl acetate-methanol-water (100: 16.5: 13.5). Re-chromatography of this fraction on silica gel column and elution with chloroform-methanolwater (90:10:1-80:20:2) afforded pure (2) as a whitish amorphous solid (35 $\mathrm{mg}$ ). The acetate of $\mathbf{2}$ using the same procedure mentioned above. The acetylation product $(22 \mathrm{mg})$ was purified by CC (silica gel and ether as eluent) to obtain $\mathbf{2}$ acetate as amorphous colourless solid (12 mg).

\section{Acid hydrolysis}

$5 \mathrm{mg}$ of 2 were refluxed with $5 \mathrm{ml}$ of $1 \mathrm{~N}$ sulphuric acid for three hours. The reaction mixture was extracted with ethyl acetate and $p$-coumaric acid was detected in the concentrated extract by TLC comparison with an authentic sample (silica gel $\mathrm{GF}_{254}$, chloroform-methanol, $\quad 90: 10 \quad$ as solvent system and ferric chloride spray). The acidic mother liquor was neutralised with barium carbonate and the precipitate filtered out and washed with distilled water. The combined filtrate and washings were evaporated to dryness and the residue redissolved in pyridine and D-glucose was detected by TLC (cellulose $\mathrm{F}_{254}, \mathrm{n}$ butanol-pyridine-acetic acid-ethyl acetate-water, 50:20:10:25:20) and aniline hydrogenphthalate as a spray reagent.

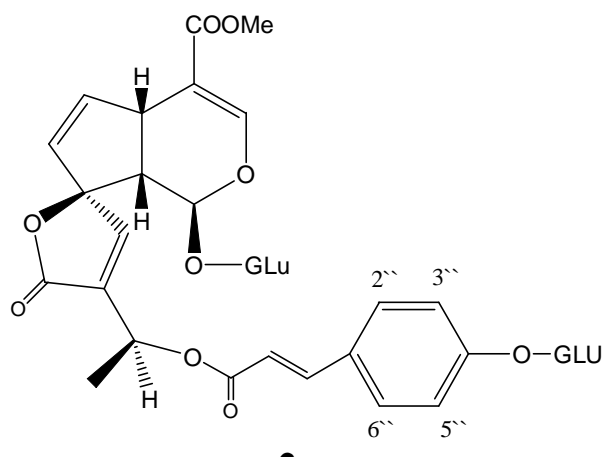

2

Compound 3 was obtained from fraction $E$ of the n-butanol extract of the leaves $(70 \mathrm{mg})$, eluted with ethyl acetate-metahnol-water (100:16.5:13.5). It crystallized out on concentration as colourless plates (45 $\mathrm{mg}$ ). 


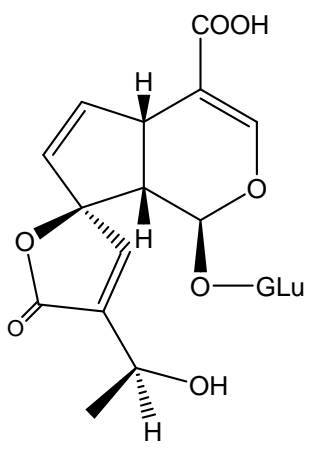

3

Plumieride (1): m.p 185-187, UV $\lambda_{(\max )} \mathrm{MeOH} \mathrm{nm} 238, \mathrm{IR} \mathrm{cm}^{-1}: 3380$, $1755,1690,1635$, positive FAB MS, $\mathrm{m} / \mathrm{z}$ (rel. int.): $471\left[\mathrm{M}+\mathrm{H}^{+}\right]$(12), 309 $\left[\mathrm{M}+\mathrm{H}-\mathrm{C}_{6} \mathrm{H}_{11} \mathrm{O}_{5}\right](100),{ }^{1} \mathrm{H}$ and ${ }^{13} \mathrm{C}$ data are listed in Tables 1, 2.

Plumieride aceate: m.p 158- $160^{\circ}$; UV $\lambda_{(\max )} \mathrm{MeOH} \mathrm{nm} 234$; IR $\mathrm{cm}^{-1}$ 1760, 1705, 1635; positive FAB MS $\mathrm{m} / \mathrm{z}$ (rel. int.) 681 (100), ${ }^{1} \mathrm{H}-\mathrm{NMR}$ data are listed in Table 1.

Protoplumericin A (2): UV $\lambda_{\text {(max) }}$ $\mathrm{MeOH} \mathrm{nm}$ 224,298 and 309; IR $\mathrm{cm}^{-1}$ : 3420, 1750, 1705, 1685, 1672, 1635, $1603,1510$.

Protoplumericin A acetate: UV $\lambda_{\text {(max) }} \mathrm{MeOH} \mathrm{nm} 322 ; \mathrm{IR} \mathrm{cm}^{-1} 1755$, $1745,1685,1635,1600,1510,{ }^{1} \mathrm{H}-$ NMR data are listed in Table 1.

Plumieride acid (3): m.p 230-232 UV $\lambda^{\mathrm{MeOH}} \mathrm{nm} 240 ; \mathrm{IR} \mathrm{cm}^{-1}: 3380-$ 3340, 1769, 1690, 1640; negative FAB MS m/z (rel. int.) 456 [M-] (20), $455[\mathrm{M}-\mathrm{H}]$ (39), $293\left[\mathrm{M}-\mathrm{C}_{6} \mathrm{H}_{11} \mathrm{O}_{5}\right]$

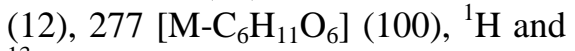
${ }^{13} \mathrm{C}$ data are listed in Tables 1, 2.

\section{Antimicrobial activity}

The three irridoids were tested against four pathogenic organisms, viz., Staphylococcus aureus, Bacillus subtilis, Escherichia coli and Candida albicans following the seeded agar method. ${ }^{8}$ The test compounds were dissolved in DMSO and added at concentrations of $0.5 \mu \mathrm{g} \mathrm{ml}^{-1}$. Results are cited in Table 3.

\section{RESULTS AND DISCUSSION}

Compound 1 showed a molecular ion peak at $\mathrm{m} / \mathrm{z} 471$ in positive FABMS $\left(\mathrm{M}+\mathrm{H}^{+}\right), \quad$ corresponding to molecular ion formula of $\mathrm{C}_{21} \mathrm{H}_{26} \mathrm{O}_{12}$. UV spectrum showed absorption maximum at $238 \mathrm{~nm}$ for the double bond of enol ether linkage conjugated to a carbonyl group $(\mathrm{O}-\mathrm{C}=\mathrm{C})$. This was confirmed by a carbonyl signal in the ${ }^{13} \mathrm{C}-\mathrm{NMR}$ spectrum at $166.8 \mathrm{ppm}$. The ${ }^{13} \mathrm{C}-\mathrm{NMR}$ spectrum also exhibited besides the six signals of $\beta$ $D$-glucose ten signals corresponding to iridoid aglycone, one due to methyl ester group at $51.2 \mathrm{ppm}$ and four due to a side chain or in a cycle. Of these ${ }^{13} \mathrm{C}$-signals, two characteristic signals were observed resonating at 96.0 and $170.5 \mathrm{ppm}$ attributed to a downfield spirocarbon, $\mathrm{C} 8$ and $\mathrm{C}=\mathrm{O}$ of $\alpha, \beta$ unsaturated lactone, $\mathrm{C} 12$, respectively. The ${ }^{1} \mathrm{H}-\mathrm{NMR}$ spectrum showed a signal due to an acetal proton at $5.15 \mathrm{ppm}(\mathrm{d}, J=5 \mathrm{~Hz})$ assigned to $\mathrm{H}-1$, as well as a downfield olefinic proton signal of $\mathrm{H}$ 3 characteristic to most iridoids (7.45 ppm, $\mathrm{d}, J=1.0 \mathrm{~Hz})^{9}{ }^{9}$ In addition, 
Table 1: ${ }^{1} \mathrm{H}$ NMR data of compounds 1-3, 1 and $\mathbf{2}$ acetates*.

\begin{tabular}{|c|c|c|c|c|c|}
\hline $\mathrm{H}$ and $\mathrm{C} \#$. & $\begin{array}{c}\text { Compound } 1 \\
\left(\mathrm{DMSO}-d_{6}\right)\end{array}$ & $\begin{array}{c}\text { Acetate of } 1 \\
\left(\mathrm{CDCl}_{3}\right)\end{array}$ & $\begin{array}{l}\text { Compound } 2 \\
\left(\mathrm{DMSO}-d_{6}\right)\end{array}$ & $\begin{array}{l}\text { Acetate of } 2 \\
\left(\text { acetone- } \mathrm{d}_{3}\right)\end{array}$ & $\begin{array}{l}\text { Compound } \mathbf{3} \\
(\mathrm{DMSO}-d 6)\end{array}$ \\
\hline 1 & $5.15, \mathrm{~d}, 5.0$ & $5.39, \mathrm{~d}, 5$ & $5.20, \mathrm{~d}, 6$ & $4.85-5.60$ & $5.11, \mathrm{~d}, 6$ \\
\hline 3 & $7.49, \mathrm{~d}, 1.0$ & $6.9, \mathrm{~s}$ & $7.52, \mathrm{~d}, 2$ & $7.35, \mathrm{~d}, 2$ & $7.26, \mathrm{~d}, 1.0$ \\
\hline 5 & $3.80, \mathrm{dd}, 9,2.5$ & $4.22, \mathrm{dd}, 9.25$ & $3.85, \mathrm{~m}$ & $4.29, \mathrm{~m}$ & $3.65, \mathrm{~m}$ \\
\hline 6 & $6.36, \mathrm{dd}, 5.5,2$. & $6.4, \mathrm{~m}$ & $6.40, \mathrm{dd}, 5,2.5$ & $6.45, \mathrm{~m}$ & $6.40, \mathrm{dd}, 7,5$ \\
\hline 7 & $\begin{array}{c}5.55, \mathrm{dd}, 5.5 \\
2.0\end{array}$ & $5.60, \mathrm{~m}$ & $5.56, \mathrm{~m}$ & $5.57, \mathrm{~m}$ & $5.52, \mathrm{dd}, 8,3$ \\
\hline 9 & $\begin{array}{c}2.80, \mathrm{dd}, 7.6 \\
4.6\end{array}$ & $3.10, \mathrm{~m}$ & $2.8, \mathrm{t}, 6.7$ & $3.05, \mathrm{dd}, 5.2,5$ & $2.77, \mathrm{~m}$ \\
\hline 10 & $7.25, \mathrm{~d}, 1.0$ & $7.32, \mathrm{~s}$ & $7.59, \mathrm{~d}, 2$ & $7.44, \mathrm{~d}, 2$ & $7.42, \mathrm{~s}$ \\
\hline 13 & $\begin{array}{c}4.36, \mathrm{dq}, 6.0, \\
3.5\end{array}$ & $5.09, \mathrm{~m}$ & $5.56, \mathrm{~m}$ & $5.57, \mathrm{~m}$ & $4.35, \mathrm{q}$ \\
\hline 14 & $1.27, \mathrm{~d}, 6.5$ & $1.48, \mathrm{~d}, 6.5$ & $1.45, \mathrm{~d}, 6.5$ & $1.57, \mathrm{~d}, 6.5$ & $1.26, \mathrm{~d}, 7$ \\
\hline $16(\mathrm{OMe})$ & $3.65, \mathrm{~s}$ & $3.75, \mathrm{~s}$ & $3.65, \mathrm{~s}$ & $3.75, \mathrm{~s}$ & - \\
\hline Acetate & - & $1.90-2.15$ (5 singlets) & - & $1.85-2.21$ (8 singlets) & - \\
\hline 1 & $4.49, \mathrm{~d}, 7.5$ & $4.75, \mathrm{~d}, 7.5$ & $4.55, \mathrm{~d}, 7.5$ & $4.85-5.60$ & $4.5, \mathrm{~d}, 8$ \\
\hline $1 “$ & - & - & $4.91, \mathrm{~d}, 7.7$ & $4.85-5.60, \mathrm{~m}$ & - \\
\hline $2-5$ & $3.15-2.95, \mathrm{~m}$ & $4.85-5.11$ & $2.95-3.49$ & $4.85-5.60$ & $4.18-4.28$ \\
\hline 6 & $3.80, \mathrm{dd}, 9,2.5$ & $4.85-5.11$ & $2.95-3.49$ & $4.85-5.60$ & $3.76, \mathrm{dd}$ \\
\hline $2 “-6 ”$ & - & - & $2.95-3.49$ & $4.85-5.60$ & - \\
\hline$\beta$ & - & - & $7.63, \mathrm{~d}, 15.7$ & $7.68, \mathrm{~d}, 16$ & - \\
\hline$\alpha$ & - & - & $6.52, \mathrm{~d}, 15.7$ & $6.50, \mathrm{~d}, 16$ & - \\
\hline $2^{\prime \prime}, 6^{\prime \prime}$ & - & - & $7.67, \mathrm{~d}, 8.5$ & $7.70, \mathrm{dd}, 9,1.5$ & - \\
\hline $3 ", 5^{\prime \prime}$ & & & $7.05, \mathrm{~d}, 8.5$ & $7.11, \mathrm{dd}, 9,1.5$ & - \\
\hline
\end{tabular}

* Spectra run at $270 \mathrm{MHz}$. 
Table 2: ${ }^{13} \mathrm{C}$ NMR data of compounds $\mathbf{1}$ and $\mathbf{3}$.

\begin{tabular}{|c|c|c|}
\hline C \# & $1 *$ & $3+$ \\
\hline 1 & 92.0 & 93.6 \\
\hline 3 & 150.5 & 153.0 \\
\hline 4 & 109.5 & 111.6 \\
\hline 5 & 41.0 & 42.8 \\
\hline 6 & 139.5 & 142.5 \\
\hline 7 & 128.5 & 131.2 \\
\hline 8 & 96.0 & 97.8 \\
\hline 9 & 48.6 & 49.4 \\
\hline 10 & 148.0 & 151.4 \\
\hline 11 & 137.7 & 139.5 \\
\hline 12 & 170.5 & 173.8 \\
\hline 13 & 60.8 & 62.4 \\
\hline 14 & 22.0 & 22.7 \\
\hline 15 & 166.8 & 170.4 \\
\hline $16(\mathrm{OMe})$ & 51.0 & - \\
\hline 1 & 98.5 & 100.0 \\
\hline 2 & 73.0 & 74.6 \\
\hline 3 & 77.1 & 78.7 \\
\hline 4 & 69.9 & 70.7 \\
\hline 5 & 76.4 & 77.9 \\
\hline 6 & 61.0 & 62.4 \\
\hline
\end{tabular}

* Spectrum run at $67.5 \mathrm{MHz}$ in DMSO- $\mathrm{d}_{6}$ † Spectrum run at $22.5 \mathrm{MHz}$ in DMSO- $\mathrm{d}_{6}$

Table 3: Results of antimicrobial activity.

\begin{tabular}{|c|c|c|c|c||}
\hline \multirow{2}{*}{ Compound } & \multicolumn{4}{|c|}{ Inhibition zone (mm)*,** } \\
\cline { 2 - 5 } & S. aureus & B. subtilis & E.coli & $\begin{array}{c}\text { C.albican } \\
\text { S.canism }\end{array}$ \\
\hline $\mathbf{1}$ & 8 & 12 & 8 & 12 \\
\hline $\mathbf{2}$ & 12 & 8 & 8 & 13 \\
\hline $\mathbf{3}$ & 15 & 14 & 8 & 10 \\
\hline
\end{tabular}

* Inhibition zone of DMSO = $6 \mathrm{~mm}$; **Inhibition zone (mm); $<7=$ inactive; 7-10 moderately active; $>10=$ strong activity 
another three signals corresponding to olefinic protons, $7.25 \mathrm{ppm}(\mathrm{d}, J=1.0$ $\mathrm{Hz}, \mathrm{H} 10)$ and two double doublets at $6.36 \mathrm{ppm}(J=5.5,2.8 \mathrm{~Hz}, \mathrm{H} 6)$ and $5.55 \mathrm{ppm}(J=5.5,2.0 \mathrm{~Hz}, \mathrm{H} 7)$ were observed indicating the presence of another two double bonds. These data, collectively, suggested that compound 1 should be an iridoid glycoside of the plumeria-type. Acetylation of $\mathbf{1}$ gave a pentaacetate derivative as indicated from the ${ }^{1} \mathrm{H}-\mathrm{NMR}$ data, Table1. The acetate derivative gave a molecular ion peak at $\mathrm{m} / \mathrm{z} 681$ $\left[\mathrm{M}+\mathrm{H}^{+}\right] \quad$ (positive $\quad$ FAB-MS) indicating a molecular formula $\mathrm{C}_{31} \mathrm{H}_{36} \mathrm{O}_{17}$. The spectral data of the aglycone moiety of compound $\mathbf{1}$ and those published for plumieride $3 \& 10$ were found to be almost identical. So the structure of $\mathbf{1}$ was established as the iridoid glycoside plumieride.

Compound 2, chromatographic behaviour, suggested a close structural relationship to plumieride. Its UV spectrum showed absorption maxima at 224, 298 and $309 \mathrm{~nm}$ indicating a plumieride moiety as well as a $p$-substituted aromatic ring. This was substantiated by the IR spectrum, which showed absorption bands at $1635 \mathrm{~cm}^{-1}$ (characteristic to $\mathrm{C}=\mathrm{C}$ of most iridoids) as well as $1750 \mathrm{~cm}^{-1}$ $(\mathrm{C}=\mathrm{O}$ of $\alpha-\beta$ unsaturated lactone characteristics to plumieride and its derivatives (Coppen, 1983). The IR showed also absorption bands at 1603 and $1510 \mathrm{~cm}^{-1}$ due to aromatic ring, 1705 and $1685 \mathrm{~cm}^{-1}(\mathrm{C}=\mathrm{O}$ of $\alpha-\beta$ unsaturated esters). Thus the UV and
IR data suggested a cinnamoyl derivative of plumieride moiety. Acid hydrolysis gave p-coumaric acid and glucose as indicated by co-TLC with authentic samples. The ${ }^{1} \mathrm{H}-\mathrm{NMR}$ spectrum clearly showed one part of an $\mathrm{AA}^{`} \mathrm{BB}^{`}$ system expected for a $\mathrm{p}$ disubstituted benzene ring at 7.05 ppm (d, $\left.J=8.5 \mathrm{~Hz}, \mathrm{H} 3{ }^{\prime \prime}, 5^{\prime \prime}\right)$. The other part was detected by means of 2D-NMR at $7.62 \mathrm{ppm}(\mathrm{d}, J=8.5 \mathrm{~Hz}$, $\mathrm{H} 2{ }^{\prime \prime}, 6$ "). The trans disubstituted side chain was proven by the large coupling constant $(J=15.7 \mathrm{~Hz})$ between two doublets at $7.63 \mathrm{ppm}$ ( $\beta$ proton) and $6.52 \mathrm{ppm}(\alpha$-proton). The chemical shifts and coupling constants of the protons belonging to the iridoid moiety of the molecule were nearly identical to the corresponding protons of compound 1. These data suggested 2 to be a pcoumaroyl derivative of plumieride. The site of acylation was proved to be at the hydroxyl group at $\mathrm{C}-13$ rather than one of the sugar hydroxyls, due to the observed downfield shift $(+1.20 \mathrm{ppm})$ exhibited by this proton compared to compound $\mathbf{1}$. This was additionally confirmed by comparing the chemical shifts of the proton at C13 of 2 and its acetate derivative (Table 1). The absence of an aromatic acetate group in the ${ }^{1} \mathrm{H}-\mathrm{NMR}$ spectrum of the acetate derivative indicated that the $\mathrm{OH}$ group at $\mathrm{C}-4$ of the $p$-coumaric acid is $\mathrm{O}$-substituted. Addition of an alkali $(\mathrm{NaOH})$ to a methanolic solution of compound 2 failed to produce a bathochromic shift in its UV absorption maxiam at $\lambda$ max nm 309, 298 and 224 nm, which also 
confirmed that the phenolic hydroxyl group is O-substituted. Oglycosylation at this $\mathrm{OH}$ seemed probable due to the detection of a second anomeric proton in the ${ }^{1} \mathrm{H}$ NMR spectrum of compound $\mathbf{2}$ at $4.91 \mathrm{ppm}(\mathrm{d}, J=7.5 \mathrm{~Hz})$ and was confirmed by the formation of an octa-acetate derivative as indicated in the ${ }^{1} \mathrm{H}-\mathrm{NMR}$ spectrum of $\mathbf{2}$ acetate (Table 1). Acid hydrolysis of compound 2 resulted in the detection of D-glucose as the only sugar confirming that the second sugar is glucose too. The configuration at $\mathrm{C}-1$, C-5 and C-9 was assumed to be similar to those of compound $\mathbf{1}$ based on measuring the ${ }^{1} \mathrm{H}-{ }^{1} \mathrm{H}$ homonuclear COSY spectrum of 2 . These data concluded that compound [2] is $13-\mathrm{O}$ [ $p$-O-( $\beta$-D-glucopyranosyl) transcinnamoyl] plumieride (plumieride coumarate glucoside or protoplumericin A). This is the first report for the isolation of this compound from Plumeria alba L. It was previously detected on TLC in ethanolic extract of this plant. ${ }^{11}$

Protoplumericin A and plumeride acid showed a strong activity against $S$. aureus, while the major compound plumieride showed only strong activity against $B$. subtilis. The three compounds were strongly active against $C$. albicans, while none of them was active against $E$. coli (Table 3).

Compound 3, its colour reaction, on TLC indicated that it is an analogue to compound 1. Negative FAB MS gave a molecular ion peak at $m / z \quad 456$ corresponding to a molecular formula of $\mathrm{C}_{20} \mathrm{H}_{24} \mathrm{O}_{12}$. The ${ }^{1} \mathrm{H}-\mathrm{NMR}$ spectrum revealed close similarity to that of $\mathbf{1}$ except for the absence of the methyl ester signal at $3.65 \mathrm{ppm}$. The ${ }^{13} \mathrm{C}-\mathrm{NMR}$ spectrum showed a total of twenty signals. Analysis of the spectrum showed also close similarity to plumieride, again with the absence of the methyl ester, C-16 at $51.0 \mathrm{ppm}$. A downfield signal at $170.4 \mathrm{ppm}$ was assigned for a carboxylic group, which showed a singlet in the ${ }^{1} \mathrm{H}-\mathrm{NMR}$ at $8.62 \mathrm{ppm}$ due to $\mathrm{COOH}$ proton. Thus, compound 3 was concluded to be 15demethyl plumieride or plumieride acid. This compound was previously reported in the bark of Plumeria rubra $\mathrm{L}^{6}{ }^{6}$ This is the second report for the isolation of plumieride acid from a natural source and the first for its isolation from Plumeria alba L.

\section{REFERENCES}

1- B. Bever, "Medicinal Plants in Tropical West Africa", Cambridge University Press, 1986, pp.12-152.

2- G. Adam, N. H. Khoi, C. H. R Bergner and N. T. Lien, Phytochemistry, 18, 1399 (1979).

3- J. W. Coppen, ibid., 22, 179 (1983).

4- O. Franca, R. Brown and C. Santos, Fitoterapia, 71, 208 (2000).

5- S. Kardono, S. Tsauri, K. Padmwinata and A. Kinghorn, Phytochemistry, 29, 2995 (1990a). 
6- L. Kardono, S. Tsauri, K. Padmawinata, J. Pezzuto and A. Kinghorn, J. Nat. Prod., 53, 1447 (1990b).

7- G. Mahran, S. Abdel-Wahab and A. Salah, Egypt. J. Pharm. Sci., 15, 226 (1974).

8- D. Groge and W. Randall, "Assay Method of Antibiotics". A Laboratory Manual, New York Medical Encyclopedia, 1955, p. 91.
9- C. A. Boros and F. R. Stermitz, J. Nat. Prod., 54, 1137 (1991).

10- F. Abe, R. Chen and T. Yamauchi, Chem. Pharm. Bull., 36, 2784 (1988).

11- J. W. Coppen and A. Cob, Phytochemistry, 22, 125 (1983). 